\title{
Analytical Method for Reduction of Residual Stress Using Low Frequency and Ultrasonic Vibrations
}

\author{
Shigeru Aoki ${ }^{1 *}$ Tadashi Nishimura ${ }^{1}$ Tetsumaro Hiroi ${ }^{1}$ \\ Katsumi Kurita ${ }^{1}$ Seiji Hirai ${ }^{2}$ and Shigeomi Koshimizu ${ }^{3}$ \\ ${ }^{1}$ Monozukuri Department, Tokyo Metropolitan College of Industrial Technology, 1-10-40 Higashi-Ohi, Shinagawa-ku, Tokyo, Japan \\ ${ }^{2}$ Department of Manufacturing Technologist, Institute of Technologist, 333 Maeya, Gyoda-city, Saitama, Japan \\ ${ }^{3}$ Master Program of Innovation for Design and Engineering, Advanced Institute of Industrial Technology, \\ 1-10-40 Higashi-Ohi, Shinagawa-ku, Tokyo, Japan \\ *aoki@s.metro-cit.ac.jp
}

Keywords: Welding, Residual stress, Mold, Repair welding, Plastic deformation.

Introduction Welding is widely used for construction of many structures. It is well known that residual stress is generated near the bead because of locally given heat ${ }^{(1)}$. Tensile residual stress on the surface degrades fatigue strength $^{(2)}$. On the other hand, welding is used for repair of mold and die. In this paper, a new method for reduction of residual stress of welded joint is proposed because of protection from crack of welded part in mold and die. In this method, low frequency and ultrasonic vibrations are used during welding. Thick plates are used as specimens of mold and die. Residual stresses are reduced when low frequency and ultrasonic vibrations are used during welding. Experimental results are examined by simulation method using an analytical model.

Experiment Using Low Frequency and Ultrasonic Vibrations Thick plate shown in Fig.1 is put onto the supporting plate and shaken by low frequency and ultrasonic vibrations during welding. Welding is completed through one pass. The frequency of low frequency vibration is chosen as $100 \mathrm{~Hz}$ and that of ultrasonic vibration is chosen as $37.5 \mathrm{kHz}$. For comparison, some specimens are welded without vibration. Figure 2 (a) and (b) show residual stresses on the bead using low frequency and ultrasonic vibrations, respectively. $\bigcirc$ shows residual stresses of specimen welded without vibration. shows residual stress using vibrations. Tensile residual stresses are measured at all points. Especially, high tensile residual stress is measured at center of the bead in case without vibrations. Tensile residual stress is reduced using vibrations.

Analytical Method Yield stress immediately after welding is very low. Then, plastic deformation is generated by low external load. Residual stress is reduced by release of strain caused by plastic deformation. One mass model considering plastic deformation is used as an analytical model. From simulation method considering this condition, reduction of residual stress near center of the bead is examined qualitatively. It is found that residual stress is reduced when low frequency and ultrasonic vibrations are used during welding.

Conclusions The effect of low frequency and ultrasonic vibrations on reduction of residual stress of repair welding for die and mold is examined by experiment and analysis. When vibrations are not used, high tensile stress is measured at center of the bead. Tensile residual stress is reduced using low frequency and ultrasonic vibrations.

\section{References}

(1) Mele, E., Calado,L. and Luca,A.D., Experimental Investigation on European Welded Connections, J. Structural Engineering, ASCE, 129-10 (2003), pp.1301-1311.

(2) Frost,N.E., Marsh,K.J. and Pook,L.P., Metal Fatigue, Dover, New York, (1999), pp.332-337.
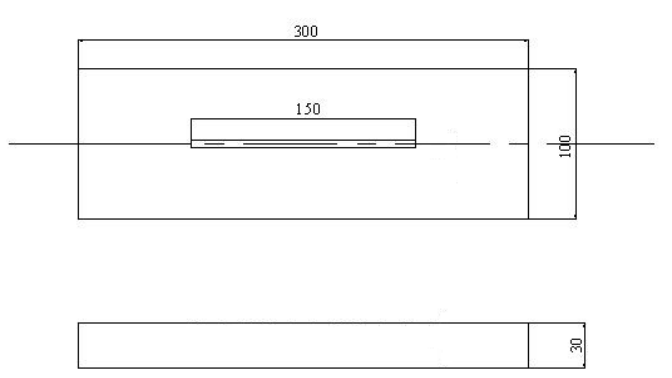

Fig.1 Size of specimen (mm)

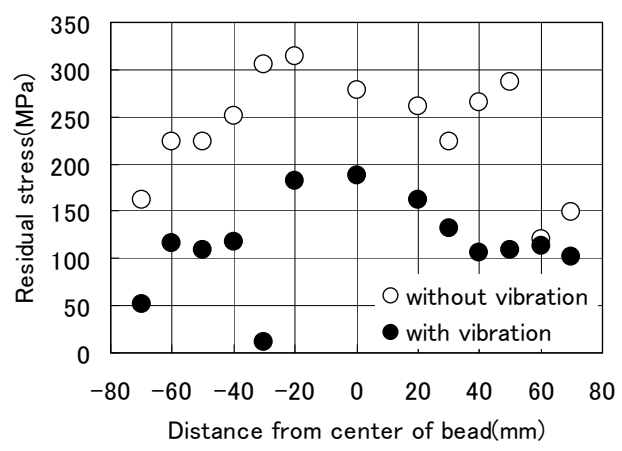

(a) low frequency vibration

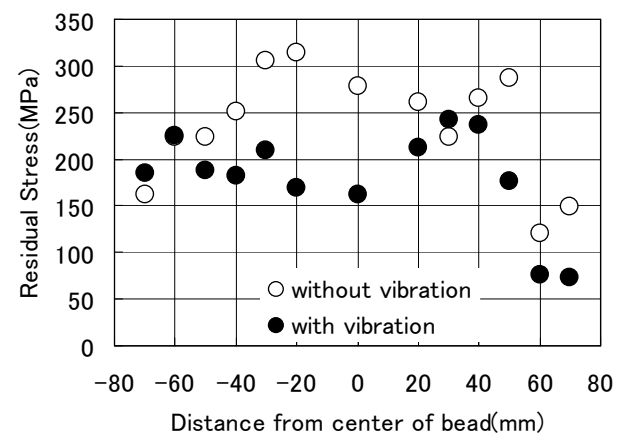

(b) ultrasonic vibration

Fig.2 Residual stress on the bead 